\title{
Measurement and analyses of biodiversity conservation actions of corporations listed in the Brazilian stock exchange's corporate sustainability index
}

\author{
Ricardo Reale ${ }^{a,{ }^{*}}$, Teresa Cristina Magro ${ }^{a}$, Luiz César Ribas ${ }^{b}$ \\ a Natural Protected Areas Laboratory (LANP), Department of Forest Sciences, Escola Superior de Agricultura "Luiz de Queiroz" (ESALQ), Universidade de São \\ Paulo (USP), Av, Pádua Dias, 11, Piracicaba, SP CEP 13418-900, Brazil \\ b Department of Economy, Sociology e Technology, Faculdade de Ciências Agronômicas (FCA), Universidade Estadual Paulista "Júlio de Mesquita Filho" \\ (UNESP) Campus Botucatu, Fazenda Lageado, s/n, Botucatu, SP CEP 18610-307, Brazil
}

\section{A R T I C L E I N F O}

\section{Article history:}

Received 6 January 2017

Received in revised form

13 September 2017

Accepted 13 September 2017

Available online 15 September 2017

\section{Keywords:}

Biodiversity conservations

Ecosystem services

BM\&FBOVESPA (B3)

Sustainability

ISE portfolio

\begin{abstract}
A B S T R A C T
Anthropization of natural areas accelerated biodiversity loss and climate changes. Thus, it is imperative that all economic sectors adjust to sustainability precepts, collaborating to the maintenance of ecosystems. Therefore, we questioned: Are sustainable companies developing sufficient actions to preserve and/or conserve biomes where they are installed? To answer, we estimated the biodiversity impacts on the Brazilian biomes developed by 11 companies which's participated, uninterruptedly, in all ISE portfolios between 2005 and 2014. We used the LIFE certification methodology (Lasting Initiative for Earth) to qualify and quantify the minimum externalities, and mitigations of each corporation. Ten corporations generated $96 \%$ of total externalities, while mitigated only $10 \%$. One financial institution did not develop mitigations, and one company of chemical/petrochemical sector described biodiversity in Brazil as irrelevant and insignificant. Only company of paper/cellulose mitigated their externalities. This company developed $77 \%$ of total scores calculated, by creating 41,600 ha of Protected Areas. Thus, the forest sector mitigated $30 \%$ of total externalities calculated for the 11 companies. That is, the organizations analyzed here demonstrated that they do not yet internalize the importance of promoting biodiversity conservation actions as a way to minimize their impacts. The LIFE certification methodology can be considered an additional tool for environmental management, indicating areas in which a company has the potential to improve management through the calculus of partial results of externalities. Also, the methodology allows for the strengthening of transparency of sustainability of companies on the Brazilian Stock Exchange (B3) and society as a whole, once the mitigation of environmental impacts through biodiversity conservation actions contributes to promoting the resilience and resistance of ecosystems, allowing the maintenance of ecosystem services, generating social welfare, economic consciousness and environmental equilibrium.
\end{abstract}

๑) 2017 Elsevier Ltd. All rights reserved.

\section{Introduction}

The world production of the agriculture, industry, and energy sectors is increasing to meet the growing demand for goods and services. These three economic sectors are the most responsible for emissions of greenhouse gases, as well as contributions to global warming, climate changes, and biodiversity loss (IPCC, 2014).

The production of goods and services is directly and indirectly

\footnotetext{
* Corresponding author.

E-mail address: realericardo@usp.br (R. Reale).
}

dependent on benefits provided by ecosystems, through ecosystemic services (Sukhdev et al., 2010). However, the current models of industrial production and the format of natural resource exploitation are realized without respect to the resilience and resistance of ecosystems, causing environmental damage. Thus, it is imperative that all economic sectors adjust to sustainability precepts.

Notwithstanding, after the advent of the concept of sustainable development in 1987, several economic sectors began to develop ways to minimize their environmental impacts. Also, many conferences were held around the world with strong agreement around environmental advances, such as the 'Paris Agreement' in 2015, which promoted affirmative policies to mitigate the harmful 
effects of global warming to the environment, with biodiversity as the direct beneficiary (UNFCCC, 2015).

Accelerated deforestation associated with agricultural, industrial and urban expansions, without correct planning, has caused direct and negative impacts on natural areas. Thus, biodiversity loss and global warming accelerate the changes in biogeochemical cycles, modifying and minimizing the resilience and resistance of ecosystems to climate changes (Chapin III et al., 2000).

According to Marcondes and Bacarji (2010), since the Brundtland report in 1987, new economic, social, and environmental paradigms have been established around the world. Thus, a discussion of sustainable development has occurred with the different sectors of society, especially from an economic perspective, including the adoption of the form of transparent management and also the disclosure of social and environmental reports.

The financial sector, particularly the stock exchanges, began to encourage and promote sustainable development in companies and also for stakeholders, by divulging and disseminating corporate sustainability indexes. These lists show the businesses that have the most sustainable practices among all participating companies of the same stock exchange after an internal selection process. These sustainable lists give an investor assurance that listed companies have environmental, economic and social advantages, such as improved environmental performance, compared with others that are not listed.

In 2005, the Sao Paulo Stock Exchange, BM\&FBOVESPA, currently ${ }^{1} \mathrm{~B} 3$ (Brasil, Bolsa, Balcão), was the fourth stock exchange in the world to release a Corporate Sustainability Index (ISE Índice de Sustentabilidade Empresarial - in Portuguese), after the USA (1999), the UK (2001) and South Africa (2003). To enter or to stay in the ISE, open capital companies need to participate annually in the selective process developed by B3 (Brasil, Bolsa, Balcão). Thus, only enterprises that have sustainable management that meets the requirements drawn up can take part in this list. The selective process is prepared and certified by the Sustainability Research Center (GVces) at Getulio Vargas Foundation's Business School (FGV-EAESP), being the B3 is responsibly to the calculus of admission and to the technical management index.

Only companies that have serious commitments to social, economic and environmental fields in their administrative systems can remain on this list, due to the great competition between enterprises to enter this prestigious list in the face of increased market visibility for companies' participation (Rossi, 2009).

In 2014, B3 launched the 10th ISE list, containing 40 selected companies among 200 with higher scores in the selection process. These 40 companies represented $50 \%$ of the total market value of the shares traded on the B3. Nevertheless, 11 companies are listed for the 10th time consecutively, representing 35\% of the market value of the portfolio, or $17.5 \%$ of the total market on the Sao Paulo Stock Exchange.

To integrate with and to continue to be listed on the ISE, the selected management systems need be regularly analyzed, enabling improvement of the environmental parameters in the administration and minimizing negative externalities. This method permits the associated ecosystem to continue to provide ecosystem services. According to the precepts of the Paris Agreement prepared in the COP-21, biodiversity conservation actions should be developed in ecosystems that need to be recovered, conserved and perpetuated.

In this scope and with the focus directed toward mitigating

\footnotetext{
${ }^{1}$ In March 2017 the securities, commodities and futures exchange activities of BM\&FBOVESPA were combined with the activities of CETIP, a provider of financial services for the organized OTC (over-the-counter) market.
}

impacts on biodiversity, the LIFE Institute (Lasting Initiative for Earth) stands out. This Institute is one organization from the third sector recognized by the United Nations through the Secretariat of the Convention of Biological Diversity and Environmental Ministry of Brazil (MMA).

While continuously improving, the Institute developed an environmental certification methodology: the "LIFE certification." This methodology supports and recognizes companies, from any size or sector, that develop biodiversity conservation actions as a way to mitigate their impacts (Instituto LIFE, 2012). Also, this certification methodology allows the qualification and quantification of the major environmental impacts of the productive activities of any organization, with global applicability (Instituto LIFE, 2012). The LIFE methodology also indicates ways in which to mitigate these impacts, minimally, through a set of voluntary biodiversity conservation actions.

This methodology of certification still is the unique in the world that measures biodiversity impacts occasioned by companies and, also, indicates what is necessary for the company mitigates or minimize their impacts. Reale et al. (2016) demonstrate, that companies can use this methodology as a diagnostic tool to analyze their Environmental Management System, calculating, in the same scale of scores, how much biodiversity conservation actions will be needed to minimize and/or mitigate their impacts on nature, specifically focused on biodiversity conservation.

Under these circumstances, this study aimed to estimate the biodiversity impacts on the Brazilian biome by 11 companies that participated, uninterruptedly, in all ISE portfolios between 2005 and 2014. Therefore, these analyses consist of evaluations of whether companies have effectively contributed to the conservation, recuperation, and maintenance of ecosystems and ecosystem services through the development of biodiversity conservation actions in the biomes in which each company operates.

The hypothesis here is that the LIFE methodology might be considered an additional tool to manage systems, to help businesses, via the mitigation of environmental impacts by developing biodiversity conservation actions, to strengthen their sustainable positions on B3, as well as with other stakeholders from the market or society.

Finally, the primary objective of this study is to evaluate whether the selected companies listed on the ISE portfolio have contributed to conservation, restoration, and the maintenance of ecosystems and ecosystem services in the biomes in which they operate through biodiversity conservation actions.

\section{Material and methods}

\subsection{Data collection}

Data were collected from the 2014 environmental reports disclosed by 11 open capital companies selected for this study. We analyzed only enterprises that participated in all of the ISE's portfolios between 2005 and 2014 without interruption.

According to Beato et al. (2009), different companies of different sizes and sectors published sustainable reports to disclose their main results in economic, social and environmental fields, making their management as transparent as possible.

The socio-environmental reports from these companies are prepared annually, and they are public documents posted on the Internet websites of these enterprises. The reports are disclosed according to the environmental politics of the company in order to disseminate the annual results of business management for civil society, shareholders and all other interested parties.

All reports evaluated in this study are in agreement with the guidelines of the GRI-4G (4th version of the Global Reporting 
Initiative). This version has highlighted in the environmental section of the report the theme of biodiversity, their impacts, and mitigations. Therefore, all of the reports analyzed were prepared using the same criteria and methodology and were evaluated by the GRI before being published as to the format of the method. We read 1588 pages of socio-environmental reports on the integrated forms of 11 companies. All environmental data were collected exclusively through reading reports from 2014.

Of the 11 evaluated companies, three are financial institutions that have 14,150 bank branches distributed in all of Brazil. Four companies are industries of four different sectors (alimentary, cosmetics, chemical and petrochemical, and paper and cellulose); three are electricity generators (principally hydropower); and, finally, one is an electricity distributor. The four industries and four electricity companies represent, together, 253 subsidiaries in all biomes of Brazil.

All subsidiaries of the same companies that occupy the same state, biome and river basin had their data added and were considered to be a single subsidiary. The objective of this study was to analyze the impact on biodiversity in each biome in Brazil. Therefore, the qualifications and quantifications (calculus) were carried out in an integrated manner. That is, one subsidiary in this study may represent a set of two or more subsidiaries when presented by the state in the case of the industrial and power sectors and geographic regions for financial sectors. Since financial institutions have a huge number of bank branches distributed across Brazil, the subsidiaries were presented by Brazilian geographic regions in the North (N), South (S), Northeast (NE), Southeast (SE) and Midwest (CO). Also, this criterion respects the biomes and the river basins from each region, following the percentage present on the socio-environmental reports from each of the three financial institutions evaluated.

This way, 14,403 subsidiaries (14,150 bank branches plus 253 industrials and electrical subsidiaries) are represented by 69 sampling subsidiaries that were qualified and quantified in this study. Of these, 54 industrial and electrical subsidiaries were divided by Brazilian states, and 15 subsidiaries of financial institutions were shared by five Brazilian geographic regions by percentage according to the integrated reports.

The reports and the collected data were standardized by the LIFE certification methodology 3.0, which was used as a tool to qualify and quantify the impacts and probable and possible mitigations that companies reported developing.

The LIFE methodology recognizes companies that develop biodiversity conservation actions voluntarily, which should minimize and mitigate the impacts occasioned by their production processes, aiming toward the sustainable uses of natural resources and biodiversity.

Also, this study used a widely disseminated and accepted Geographic Information System (Google Earth, for example) to draw maps.

\subsection{Methodological scheme for data analysis}

The LIFE certification methodology realizes an environmental diagnosis of management systems (Reale et al., 2016), qualifying and quantifying the main environmental impacts (externalities) through parameters that make up the "BEIV" (Biodiversity Estimated Impact Value) and "BCA min" (Biodiversity Conservation Actions minimum) (Instituto LIFE, 2014a). In this sense, the BEIV indicates, indirectly, the minimum impact determined for one company in their ecoregion inside a biome using scores that vary from 0 to 1000 (without units). On the other hand, the calculus of

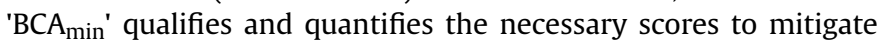
and minimize the calculated scores in the BEIV (Instituto LIFE, 2014b).

Also, ' $B C A_{\min }$ ' is utilized to determine the value of the score of impact on biodiversity that a company should develop in the biome to mitigate their impact. Thus, comparing the scores of ' $\mathrm{BCA}_{\min }$ ' (value of scores in conservation actions that companies should

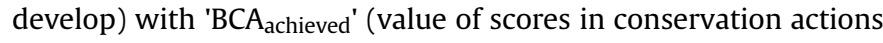
achieved by the evaluated companies) can give an overview of the environmental situation between enterprise and its biome that is home.

All collected data were used to fill the dependent variables in the spreadsheets "Evaluation of BEIV," "BCA $A_{\min } 3.0$ " and "BCA $A_{\text {achieved". }}$ These worksheets are a tool used by auditors trained and qualified by the LIFE Institute for the achievement of certification audits and the monitoring of certification actions. Also, they can be used by companies that would like to be adequate to receive the certification.

\subsection{Calculations of impacts and mitigations on biodiversity}

The Biodiversity Estimated Impact Value (BEIV) is quantified and qualified by five environmental aspects from the EMS (Environmental Management System): 1) occupation area (ha); water usage ( $\mathrm{m}^{3} /$ annum); 3 ) electricity energy consumption (TeP/annum) (equivalent tons of petroleum/annum), considering all energy matrixes of the company; 4) GHG emissions, considering the total $\mathrm{tCO}_{2} \mathrm{e} / \mathrm{annum}$ (tons of $\mathrm{CO}_{2}$ equivalent/annum); and 5) tons of waste generation per annum, differentiating between hazardous and nonhazardous. For the calculation of the $\mathrm{BCA}_{\min }$, the company's gross revenue is also considered, in American dollars.

Thus, it is possible to observe the areas of the business that need improvement in environmental management, while the $\mathrm{BCA}_{\mathrm{min}}$ indicates the score that should be developed for the use of the environmental resources by companies in order to respect the resilience and resistance of ecosystems (Reale et al., 2016). Thereby, the authors demonstrated qualitative and quantitative aspects of the BEIV and $\mathrm{BCA}_{\min }$ in a case study of the automotive industry.

The formulas used in the calculus worksheets of the BEIV and $\mathrm{BCA}_{\min }$ can be found in the technical guide LIFE-BR-TG01-3.0English (more details about how we developed the calculus can be found here: http://institutolife.org/wp-content/uploads/2015/ 07/LIFE-BR-TG01-3-0-English.pdf).

All environmental reports analyzed in this study were prepared in the integrated format, i.e., showing that all different subsidiaries were combined and presented as a single subsidiary for the year of interest. However, through the reports, it was possible to identify the occupation area, company's gross revenue, and production of each subsidiary for the period analyzed. Thus, with these pieces of information, it was possible to calculate, proportionately, the BEIV and the BCA (by mathematic ponderation) for each environmental aspect, according to the data in the reports.

For companies that had two or more subsidiaries in the same state, biome, and hydrographic basin, we considered them as one subsidiary to calculate externalities for biomes. For example, five plants of company E1 are localized in the same state, biome and hydrographic basin. Therefore, these five plants were grouped and considered as one subsidiary in this study. The LIFE methodology quantifies the environmental aspects, transforming them into indices, as proposed in the technical guides LIFE-BR-TG01-3.0English and LIFE-BR-TG02-3.0-English.

Initially, we compared the environmental aspects with official and national standards of Brazil. Then, the results were classified according to the severity and quantity, i.e., how impactful on biodiversity and how much the organization consumes, emits or generates by each aspect. Thus, the results of the indices demonstrate, minimally, the quantity and severity of the impacts of each 
environmental aspect.

Thus, the environmental aspects were calculated and transformed into the same scale. At the end of the transformation process, the environmental aspects, which initially had different chemical and physical units, could be presented in a dimensionless scale. Consequently, it was possible to use them to calculate the BEIV and the BCA in the worksheets and make comparisons.

Therefore, the amount used, issued or generated by each environmental aspect could be used to calculate the BEIV for this subsidiary. This score can range from 0 to 1,000 , independently of their size and sector. Therefore, the BEIV will indicate the quality of management of each environmental aspect of the EMS, exclusively for the subsidiary evaluated.

\subsection{Biodiversity conservation actions achieved ( $\left.B C A_{\text {achieved }}\right)$}

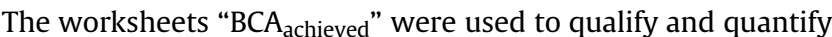
all biodiversity conservation actions achieved voluntarily by companies analyzed in this study. In this study, only conservation actions described in the socio-environmental reports with the objective of conserving the biodiversity voluntarily were considered (Instituto LIFE, 2014b).

This way, we utilized the technical guideline LIFE-BR-TG02-3.0English of the LIFE methodology as a guide tool of considered actions in the reading of reports (more details about how we developed the calculus can be found here: http://institutolife.org/wpcontent/uploads/2015/07/LIFE-BR-TG02-3-0-English.pdf). The conservation actions described in the reports were classified using the flowchart indicated in Fig. 1. Each action recognized in the reports was added to one of four big groups of conservation. The groups were structured in a decreasing hierarchy of score, representing strategic priority lines for conservation, considering the potential to generate effective results (Instituto LIFE, 2014a, 2014b).

Thus, G1 is receiving, conceptually, the highest score, followed by G2, G3, and finally, G4, which is in consonance with the sustainable principle established by REDD+.

This system of scores has incentives for more biodiversity conservation actions inside protected areas or for creating new protected areas. Thus, the preservation and perpetuation of biological diversity and, consequently, ecosystem services will be more likely.

Fig. 2 shows a scheme (script) used to guide the data collection

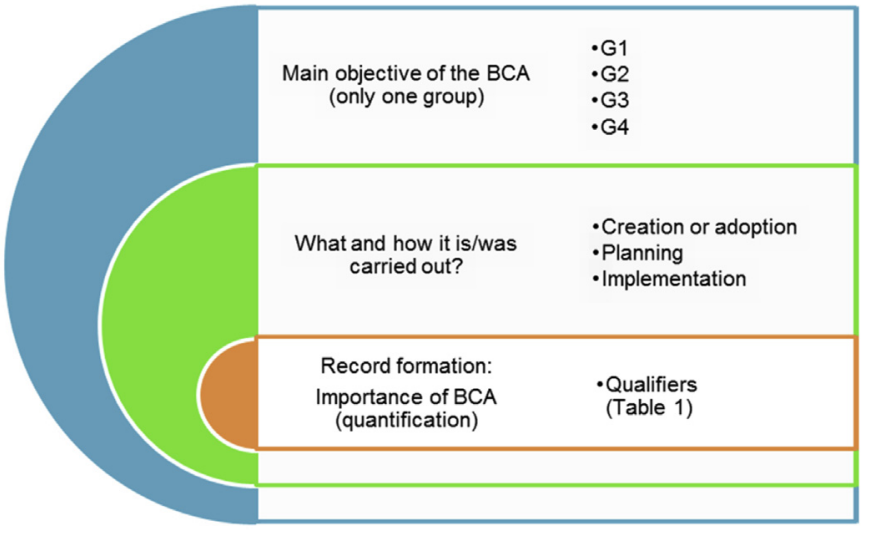

Fig. 2. Script for data collection in Sustainability Reporting. Source: Technical Guide LIFE-BR-TG02-3.0-Portuguese (Adapted)

during the reading of reports of companies. First, the supposed biodiversity conservation should be classified inside one of the four groups "G." In sequence, Table 1 is used to qualify each action described in the report, forming the LIFE record. So, in the end, the LIFE record will be put in the worksheets to score the $\mathrm{BCA}_{\text {achieved }}$ according to the richness data appointed to report on the environmental action, as shown in Table 1.

After the formation of the records, each BCA was quantified by 16 qualifiers, described in the Technical Guide LIFE-BR-TG02-3.0Português, shown in Table 1.

\section{Results and discussion}

The analyses of socio-environmental reports were conducted in conformity with the methodological script as provided in Figs. 1 and 2 . In sequence, Table 2 presents the results of collected data, with respect to the five environmental aspects, which were used to calculate the BEIV and $\mathrm{BCA}_{\text {min }}$.

All companies described the results in an integrated form, reporting environmental results of all subsidiaries. For example, one company that has 51 different subsidiaries showed all their results added together as a single subsidiary. Because of that,

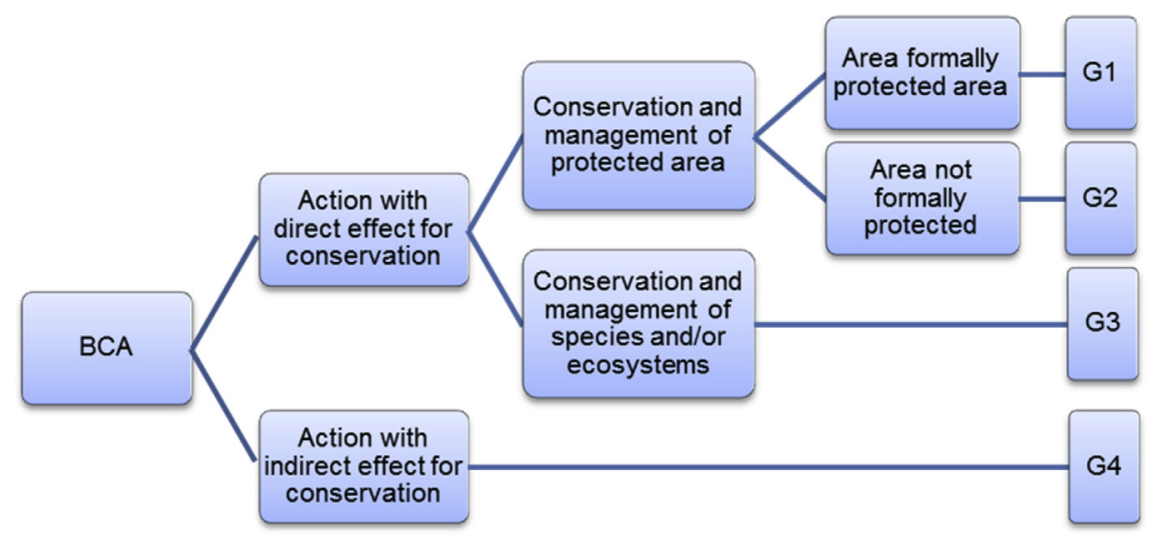

Fig. 1. Flowchart of LIFE groups' conservation.

Where:

G1-Conservation and management of formally protected areas

G2-Conservation and management of areas which are not formally protected

G3-Conservation and management of species and/or ecosystems

G4-Initiatives associated with conservation strategies, policies and/or programs.

Source: INSTITUTO LIFE 2014c (Adapted) 
Table 1

Qualifiers LIFE.

\begin{tabular}{|c|c|c|}
\hline Qualifier & Name & Description \\
\hline Q1 & $\begin{array}{l}\text { Coverage of native vegetation in a good } \\
\text { state of conservation }\end{array}$ & $\begin{array}{l}\text { Class-percentage in the recoating of native vegetation in good conservation condition (between } 50 \% \text { and } \\
100 \%)\end{array}$ \\
\hline Q2 & Coverage of the program or project & $\begin{array}{l}\text { Exclusively to the G4. Elaboration and implementation of strategic or political conservation actions. } \\
\text { Different scores to national, regional, state or local }\end{array}$ \\
\hline Q3 & The area's importance for conservation & $\begin{array}{l}\text { Classification of the area's importance for biodiversity conservation (Case of Brazil: MMA Ordinance 09/ } \\
\text { 2007) }\end{array}$ \\
\hline Q4 & Category of species threatened & Threat category according to more specific list that exists at the time (municipal, state and national) \\
\hline Q5 & CITES Appendices (2014) & Appendices I, II and III \\
\hline Q6 & $\begin{array}{l}\text { Category of management of the areas } \\
\text { which make up mosaics }\end{array}$ & $\begin{array}{l}\text { Category of Protected Areas (Priority for sustainable use; Priority for integral protection; Solely integral } \\
\text { protection) }\end{array}$ \\
\hline Q7 & $\begin{array}{l}\text { Category of potential invasive of exotic } \\
\text { species }\end{array}$ & Categories of invasion of exotic species (Contained, present, established, invasive) \\
\hline Q8 & $\begin{array}{l}\text { Mean distance and width of the } \\
\text { connection }\end{array}$ & Wildlife corridor $>30 \mathrm{~m}$ Length $>100 \mathrm{~m}$ \\
\hline Q9 & Stage of ecological succession & Initial, middle or advanced \\
\hline Q10 & $\begin{array}{l}\text { Categories of Management of Protected } \\
\text { Areas }\end{array}$ & Protected Areas (SNUC 2000) and Indigenous Lands and category IUCN 2008 \\
\hline Q11 & Duration of action & Applied when the duration of the action affects its result \\
\hline Q12 & Frequency and continuity of the action & Related to education for biodiversity conservation \\
\hline Q13 & $\begin{array}{l}\text { Link to a Management Plan or } \\
\text { equivalent }\end{array}$ & Linked to a plan of management or similar \\
\hline Q14 & Purpose of the recovery & Consider actions of ecological restoration, and actions of ecological recovery of areas \\
\hline Q15 & Size of area & Size in hectares \\
\hline Q16 & $\begin{array}{l}\text { Importance of the Ecoregion (according } \\
\text { to MMA data) }\end{array}$ & All Brazilian biomes (45 terrestrial and eight marine ecoregions). \\
\hline
\end{tabular}

Source: LIFE Institute. Technical Guide LIFE-BR-TG02-3.0-Português.

Table 2

Data collect of 11 companies analyzed in this study.

\begin{tabular}{|c|c|c|c|c|c|c|c|}
\hline \multirow[t]{2}{*}{ Companies } & \multicolumn{7}{|l|}{ Environmental Aspects } \\
\hline & Sector & $\begin{array}{c}\text { Waste generation } \\
\text { (t/year) }\end{array}$ & $\begin{array}{c}\text { GHG } \\
\left(\mathrm{tCO}_{2} \mathrm{e} / \text { year }\right)^{\mathrm{a}}\end{array}$ & $\begin{array}{l}\text { Energy Consumption } \\
\quad \text { (toe/year) }^{\mathrm{b}}\end{array}$ & $\begin{array}{l}\text { Water usage } \\
\left(\mathrm{m}^{3} / \text { year }\right)\end{array}$ & $\begin{array}{c}\text { Area occupation } \\
\text { (ha) }\end{array}$ & $\begin{array}{l}\text { Gross Revenue } \\
\text { US\$ bi/year }^{c}\end{array}$ \\
\hline E1 & Alimentary & $1,317,882$ & $3,962,223$ & $35,014,928$ & $59,639,210$ & 22,168 & 3.2 \\
\hline E2 & Financial Institution & 6211 & 244,816 & 57,879 & $1,701,748$ & 198 & 28.558 \\
\hline E3 & Financial Institution & 26,567 & 197,409 & 41,609 & $1,515,850$ & 233 & 15.962 \\
\hline $\mathrm{E} 4$ & Generating electricity & $1,849,596$ & $6,413,950$ & $4,067,789$ & $846,707,000$ & 144,915 & 0.094 \\
\hline E5 & Cosmetic & 16,487 & 332,326 & 13,623 & 294,700 & 254 & 2.8 \\
\hline E6 & Generating electricity & 364 & $1,213,775$ & 198,213 & 126,000 & 44,301 & 1.415 \\
\hline E7 & Chem/Petr/Plast & 64,968 & $300,429,932$ & $1,819,186$ & $62,793,629$ & 1650 & 17.317 \\
\hline E8 & Financial Institution & 18,820 & 111,457 & 66,686 & $1,913,768$ & 276 & 16.488 \\
\hline E9 & Paper and cellulose & $13,507,451$ & $1,288,077$ & 382,222 & $135,000,000$ & 603,000 & 3.443 \\
\hline E10 & Generating electricity & 52,641 & 617,717 & 195,594 & $1,424,540$ & $56,747,800$ & 7.356 \\
\hline E11 & Electricity Distributor & 146,799 & $6,259,972$ & $2,886,534$ & 84,563 & 452,600 & 1.291 \\
\hline
\end{tabular}

Source: Results from this research.

a Ton of $\mathrm{CO} 2$ emitted per year.

b Ton of oil equivalent per year.

c Considered Quotation for R\$1.00: PTAX US Dollar 12/31/2014 of US\$2.6562.

Table 2 presents the results for 11 companies, indicating 14,403 subsidiaries from all enterprises analyzed in this study. However, all reports analyzed in this study declared the company's gross revenue, the total area occupied, and the annual production of all subsidiaries. Thus, the environmental aspects were calculated proportionally with those data, which made it possible to calculate the BEIV and $\mathrm{BCA}_{\min }$ for all companies studied here.

The BEIV calculus shows the estimated impact on biodiversity, indicating how great the consequences of environmental aspects of this business are, varying between 0 and 1000. A BEIV close to 1000 has a significant impact on biodiversity due to the production process. In this study, the BEIV calculus was necessary to calculate the $\mathrm{BCA}_{\mathrm{min}}$, which is computed by the function of a company's gross revenue and the BEIV score, as shown in the technical guide LIFEBR-TG01-3.0-Português.

Therefore, the $\mathrm{BCA}_{\mathrm{min}}$ in this study indicates a minimum biodiversity impact developed by a determined portion of a company in a determined biome. Also, the scores are on the same scale, which makes it possible to compare all corporations and biomes in this study. That is, the $\mathrm{BCA}_{\min }$ calculates the impact on biodiversity (externalities), which should be zero. The technical guide LIFE-BRTG02-3.0-Português demonstrates all possibilities of Biodiversity Conservation Actions that can be qualified and quantified.

The companies E2, E3, and E8, are financial institutions that, together, possess 14,150 bank branches distributed in Brazil. They were represented in the socio-environmental reports by a percentage of bank branches in Brazilian geographic regions. Thus, this proportion was utilized to calculate the BEIV and $B C A_{\text {min. }}$.

Companies E1, E5, E7, and E9, are industries in four different respective sectors: alimentary, cosmetic, chemical/petrochemical/ plastic, and paper/cellulose. Companies E4, E6, and E10 generate electricity, and company E11 is an electricity distributor. All electricity generating companies possessed many types of electricity generation, with hydropower as the major production type. Together, industries and power companies totaled 253 subsidiaries in Brazil, as shown in the map in Fig. 3, where green points 


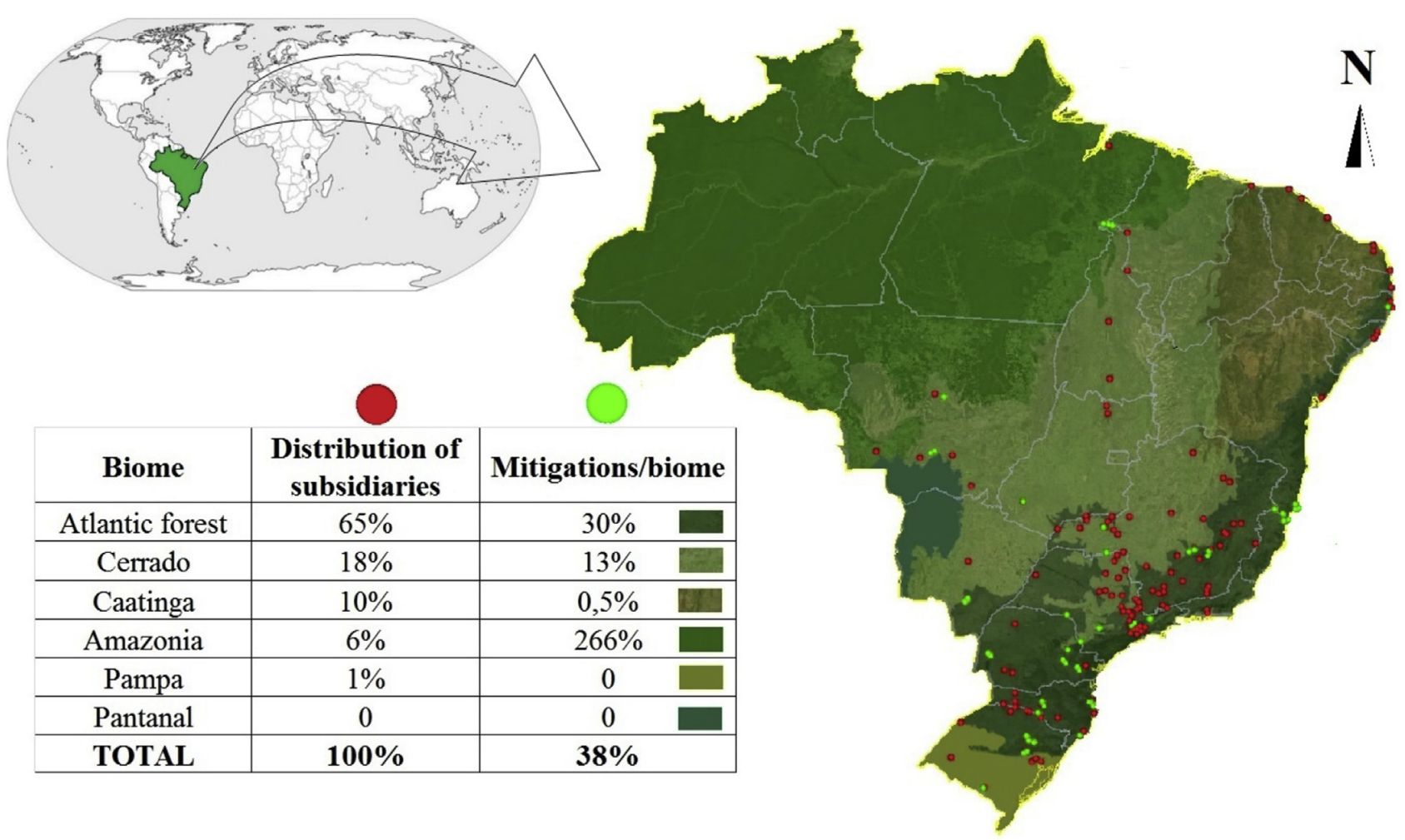

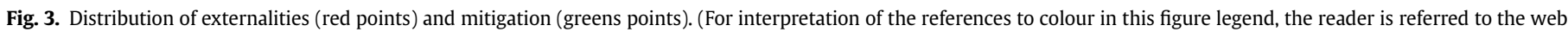
version of this article.)

Source: Brazilian biomes - IBGE, 2004 (Adapted). Rio de Janeiro - Map scale: 1:5,000,000

represent the $\mathrm{BCA}_{\min }$ (mitigation of impacts) and the red points represent the companies, which represent the externalities.

Table 3 (Appendix A) shows 69 sample subsidiaries quantified per state, hydrographic basin and biome from the 11 companies analyzed in this study, where financial institutions were presented by geographic regions because of their high number of bank branches and were calculated by their percentage as described in their socio-environmental reports. The resulting scores showed that all of the enterprises analyzed have activities that cause negative impacts on biodiversity, as indicated by the BEIV, representing the consumption of natural resources in that state, biome or hydrographic basin. That is, by the LIFE methodology, if a company had an impact on biodiversity as calculated by $\mathrm{BCA}_{\min }$, it will be necessary to achieve the same minimum scores in $\mathrm{BCA}_{\text {achieved }}$ to mitigate or minimize the externalities.

The value of BEIV, and consequently, the $\mathrm{BCA}_{\min }$, might vary according to the ecoregion of the biome in which the analyzed subsidiary is located. For this quantification, the LIFE methodology uses the criterion of occupation area for each ecoregion of the Brazilian biome, using "Ecorregiões do Brasil: prioridades terrestres e marinhas" as a published reference. Each ecoregion, together with the hydrographic basin occupied, can have a major or minor influence on the score of the BEIV and $\mathrm{BCA}_{\min }$ depending on the size of their ecoregion and the water availability of the river basin.

Below, Fig. 4 shows a graph of the results of all mitigations (in green) and externality minimums (in red) calculated for all companies and their subsidiaries presented in Table 3 (Appendix A).

The results illustrate that most of the companies do not develop biodiversity conservation actions as a way to minimize and mitigate their impacts. Only companies E6 and E9 mitigated their impacts on biodiversity. However, only company E9 had all subsidiaries describing conservation actions in the 2014 socio-environmental report. Company E6 had only two subsidiaries realizing conservation actions among the 11 subsidiaries in this study.

Company E7 does not admit that their production process produces negative impacts on biodiversity, reporting that biodiversity in Brazil 'is an insignificant or indifferent factor for their activities and their stakeholders', as stated in their socio-environmental report. Because of that statement, the permanency of E7 in the ISE portfolio should be re-evaluated once the biodiversity is indissociably a part of the environmental division of the GRI-4G format of the report. Company E7 continued in the ISE portfolio until the new portfolio in 2017, but this study did not evaluate the new reports of 2015 and 2016.

On the other side, company E9 declared in the report that the biodiversity is of "high importance for the economic, environmental and social impacts of the organization", as well as of "high influence for evaluation and decision of the stakeholders." Company E9 achieved higher scores in mitigation than all other companies. However, company E9 did not continue in the ISE portfolio in 2016 and 2017.

Complying with the environmental legislation is a mandatory requirement for any person or entity, private or governmental. Therefore, to allow participation in a portfolio that allows a $20 \%$ valuation in the stock exchange when compared to other companies that do not participate in the ISE (Rossi, 2009) exclusively by meeting legal demands is not correct from the view of biodiversity conservation and ecosystems.

The ISE assesses in an integrated way the aspects of sustainability, with the aim to instill sound management practices in the Brazilian market, becoming a reference for socially responsible investments. Thus, the sustainability index is composed of company shares with the most sustainable performance, scored by a questionnaire as a part of the selective process according to the B3. 


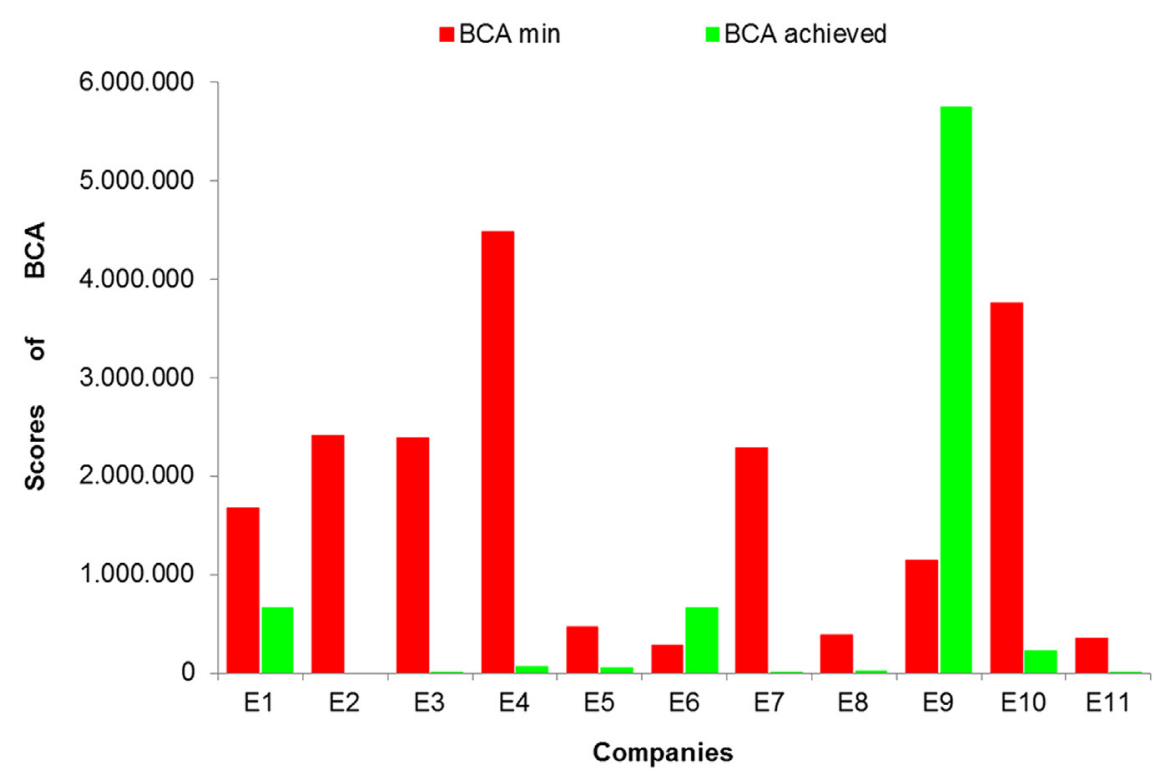

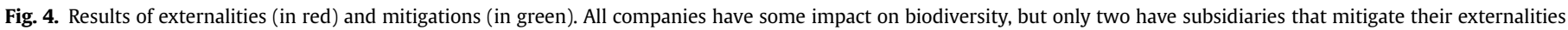
(subsidiaries of companies E6 and E9). (For interpretation of the references to colour in this figure legend, the reader is referred to the web version of this article.)

In addition to the environmental, social and economic-financial, common dimensions of the Triple Bottom Line of sustainability, the Sao Paulo stock exchange added another four dimensions: corporative governance, general, product nature, and climate change.

It is emphasized that the companies listed in the ISE portfolio, approved in the selective process, theoretically possess the best results in the aspects described above, principally by participating uninterrupted in the ISE from 2005 until 2014. Nevertheless, the best 11 companies do not present effective mitigation actions according to the LIFE methodology. Therefore, we should question the situation of enterprises that do not have the same 'environmental concern' as the companies analyzed in this study.

That is, the organizations analyzed here demonstrated that they do not yet internalize the importance of promoting biodiversity conservation actions as a way to minimize or mitigate the impacts caused by their production processes. It is highlighted, yet, that these companies are part of the same market sectors responsible for the high GHG emissions that are closely associated with climate change.

The effects of global warming are responsible for the reduction of resilience and resistance of ecosystems to climate adversity, due to biodiversity loss and minimization of ecosystem services (Cardinale et al., 2012). GHG emissions have elevated the frequency, amplitude, and gravity of climate extremes on the planet. Ecosystems with the greatest biodiversity are more stable and recover quickest from damage caused by environmental and climatic disasters. That is, according to Isbell et al. (2015), major biodiversity generates major ecosystem resistance. Consequently, the 'LIFE methodology' has been demonstrated to be an excellent tool for performing environmental assessments of the EMS (Reale et al., 2016), i.e., it may be useful to the ISE selection process by B3, as in the environmental questions of evaluations.

Table 4 (Appendix $\mathrm{B}$ ) presents the results of all $\mathrm{BCA}_{\text {achieved, }}$ which is possible to qualify and quantify by reading the environmental reports and by the LIFE methodology. Only voluntary actions were considered. Not all subsidiaries achieved some mitigation, but others developed several types of $\mathrm{BCA}_{\text {achieved }}$ with many scores. Table 4 (Appendix B) does not show the number of subsidiaries, but it shows the abundance of $\mathrm{BCA}_{\text {achieved }}$ and the individual score.

In Fig. 5, note that the companies considered as the most sustainable in the country by B3 did not develop effective conservation actions to mitigate impacts. The majority of subsidiaries do not develop or do not describe conservation actions. If companies did not describe some actions because they were reported in the year before, the reader could understand that conservation action does not exist.

The graph in Fig. 5 shows that company E9 is the organization that developed $77 \%$ of the total $\mathrm{BCA}_{\text {achieved }}$ scores out of the 11 companies analyzed in this study, inside the precepts established by the LIFE methodology. Only one subsidiary of company E9 in the Amazon biome is responsible for $42 \%$ of the total scores calculated in the $\mathrm{BCA}_{\text {achieved }}$. Two other subsidiaries are responsible for $35 \%$ of the total mitigation scores in Brazil, or $65 \%$ of the mitigations in the Atlantic Forest.

Excluding company E9, Fig. 6 shows the insignificant effect of conservation actions developed by the other 10 companies listed in the ISE portfolio. Together, these 10 companies mitigated only $10 \%$ of the $\mathrm{BCA}_{\min }$ calculated for the Atlantic Forest biome and 13\% of the Cerrado biome, as shown in Fig. 6. That is, the value of mitigation scores developed by the other 10 companies was insignificant, even though these companies represented $96 \%$ of the total subsidiaries calculated in this study.

Additionally, among the 69 subsidiaries analyzed, seven developed more mitigation actions than the minimum necessary according to the LIFE methodology. These subsidiaries are relevant examples in their biome and should be a model for other organizations to minimize and mitigate their consumption of natural resources and environmental impacts from the productive process. Since these mitigations were developed according to the LIFE methodology, they are beneficial to the conservation and maintenance of ecosystem services.

Nevertheless, the Atlantic Forest contains approximately $60 \%$ of the Brazilian population, contributing to $70 \%$ of the Gross National Product (GNP) and $66 \%$ of the industrial production of Brazil (Scarano and Ceotto, 2015). Half of this industrial amount is located in São Paulo State, Brazil's economic headquarters (30\% of GNP), which has been beset by a water crisis since 2013. However, only one company reported public policies in an attempt to initiate 


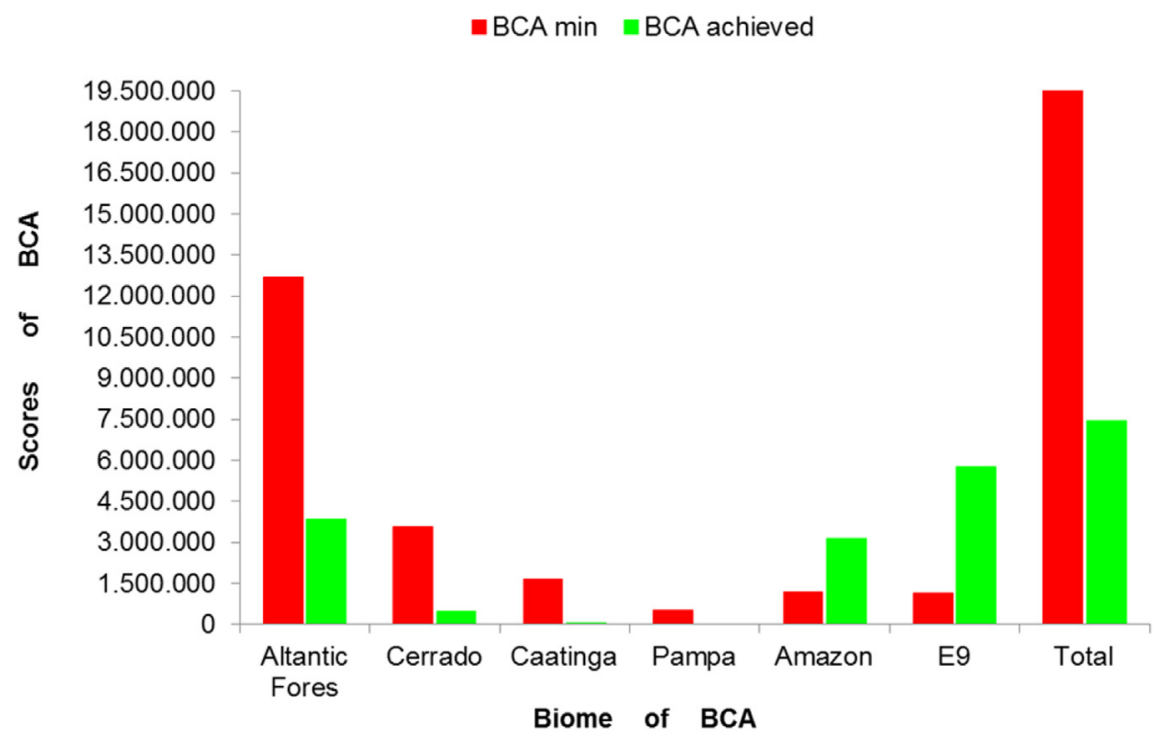

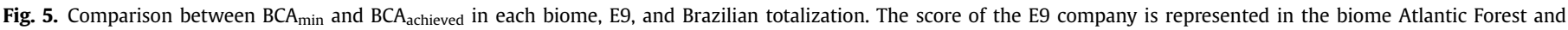
Amazon, as well as being separately presented to show the high amount of points developed by this company.

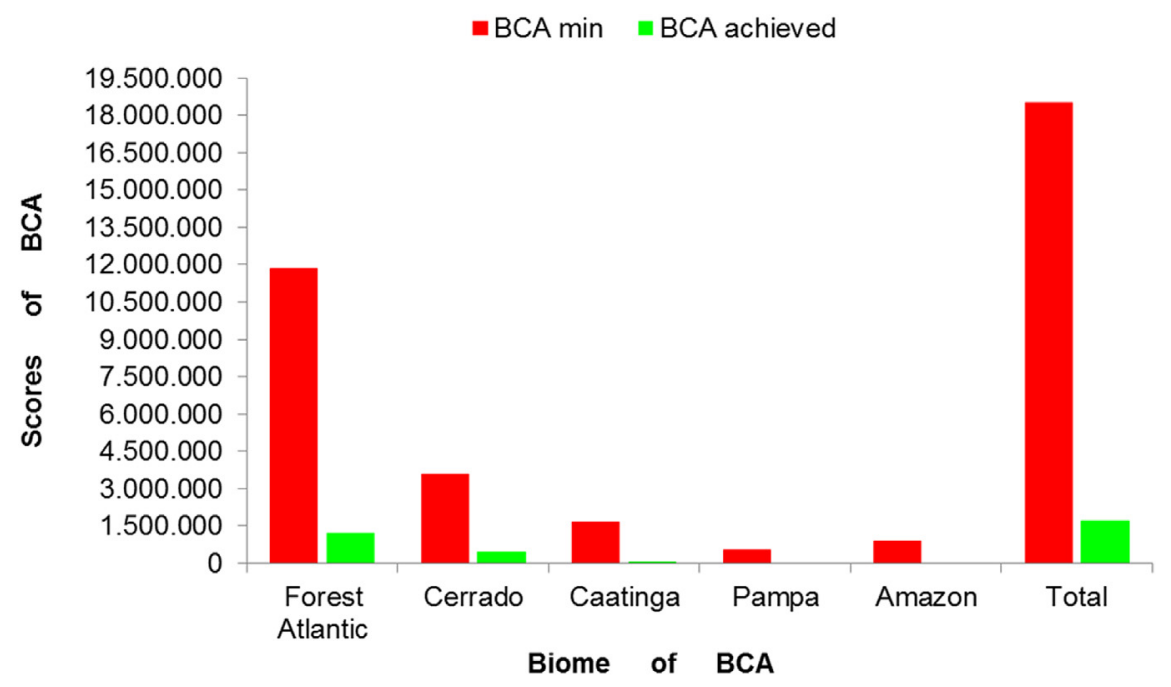

Fig. 6. Score of companies in biomes, excluding company E9.

corrective actions for the water balance in their area. However, there was only one meeting to support the competent authorities, without describing the possible measures agreed upon and without resumption of the matter. Therefore, the few actions undertaken in the State of São Paulo are insufficient given the recommendations of the LIFE method to return benefits to ecological systems.

The prolonged drought from 2013 until early 2016 that hit the economic and industrial hub of Brazil occurred due to the effect of deforestation of the rainforest, principally the Amazon Forest, and climate extremes due to global warming (Dobrovolski and Rattis, 2015). That is, the impact was maximized in the most degraded areas and high industrial concentration, such as the Atlantic Forest case and the State of São Paulo (Sheil and Murdiyarso, 2009).

Ecosystem services provide benefits to humans (Sukhdev et al., 2010), offering direct benefits such as water, energy, and food. They also provide regulatory advantages, such as water purification, flood control, and erosion. Finally, they provide indirect benefits, such as nutrient cycling, soil production, and photosynthesis (Zolin et al., 2014).
Isbell et al. (2015) suggested that biodiversity stabilizes productivity and ecosystem services, increasing the strength and resilience of ecosystems to adverse climatic events. That is, the development of conservation actions contributes to reducing or avoids drought events. Once there are no mitigating actions by enterprises, damage to biodiversity tends to perpetuate, causing decreasing environmental plasticity, resilience, and productive stability. Certainly, the lack of mitigation will increase the environmental problems and, consequently, will harm the life and economy of the region or country affected.

Few subsidiaries have developed a $\mathrm{BCA}_{\text {achieved }}$ to create or to adopt officially protected areas. The Permanent Protected Area (PPA) and Legal Reserve (LR) are obligatory by Brazilian Law to some companies. However, these two will only be considered as $\mathrm{BCA}_{\text {achieved }}$ if more conservation actions are carried out than the law requires. The biomes of the Atlantic Forest, Amazon Forest, and Cerrado were unique and received conservation actions to create or adopt protected areas. The total areas in the three biomes are 27,387 ha, 25,600 ha, and 2098 ha, respectively. 
However, the 25,600 ha in the Amazon and the 16,000 ha in the Atlantic Forest are exclusively responsibilities of company E9. That is, $75 \%$ of the created areas were from the same company. The total area reported by company E9 was clearly a voluntary disclosure, not adding PPA or LR from the enterprises.

In this context, only 20 subsidiaries (of 68 evaluated) protect biodiversity directly by actions to create or adopt protected areas. However, some areas that were created, despite important conservation actions, were too small or incipient, like 10,13 or 18 ha of native forest. It is always important to protect biodiversity directly, through protected areas of native vegetation. However, only creating a protected area without connectivity to other larger fragments may undermine or derail this important conservation action, since the fragmentation of habitats can lead many species to extinction in addition to the areas not being able to exercise their ecological role (Andam et al., 2008; Auffret et al., 2015; Rambaldi and de Oliveirade, 2003; Ribeiro et al., 2009; Sícoli et al., 2005; Williams et al., 2010). Additionally, small forest fragments contribute to the extinction of big mammals, contributing to defaunation, empty forests, and also negatively affecting carbon storage (Bello et al., 2015; Vincent et al., 2014).

Fig. 7 shows all subsidiaries of companies E1, E6, and E9 that had the highest percentage of mitigations. This group developed the highest value in scores in this study, realizing biodiversity conservation actions that mitigated more than $100 \%$ of their externalities. Of the 68 grouped subsidiaries analyzed, only seven developed mitigations sufficient to minimize their externalities.

Fig. 8 shows the subsidiaries that mitigated between $5 \%$ and 70\%. Also, it shows that institution E8 is due to develop a high number of different BCA in some Brazilian biomes. However, their BCA scores were low in each biome, but they were the only enterprise with conservation actions across the country, in a fair and balanced way, but the actions were not sufficient to mitigate their calculated impacts.

The low scoring of several subsidiaries may have occurred because all socio-environmental reports followed the criteria of the

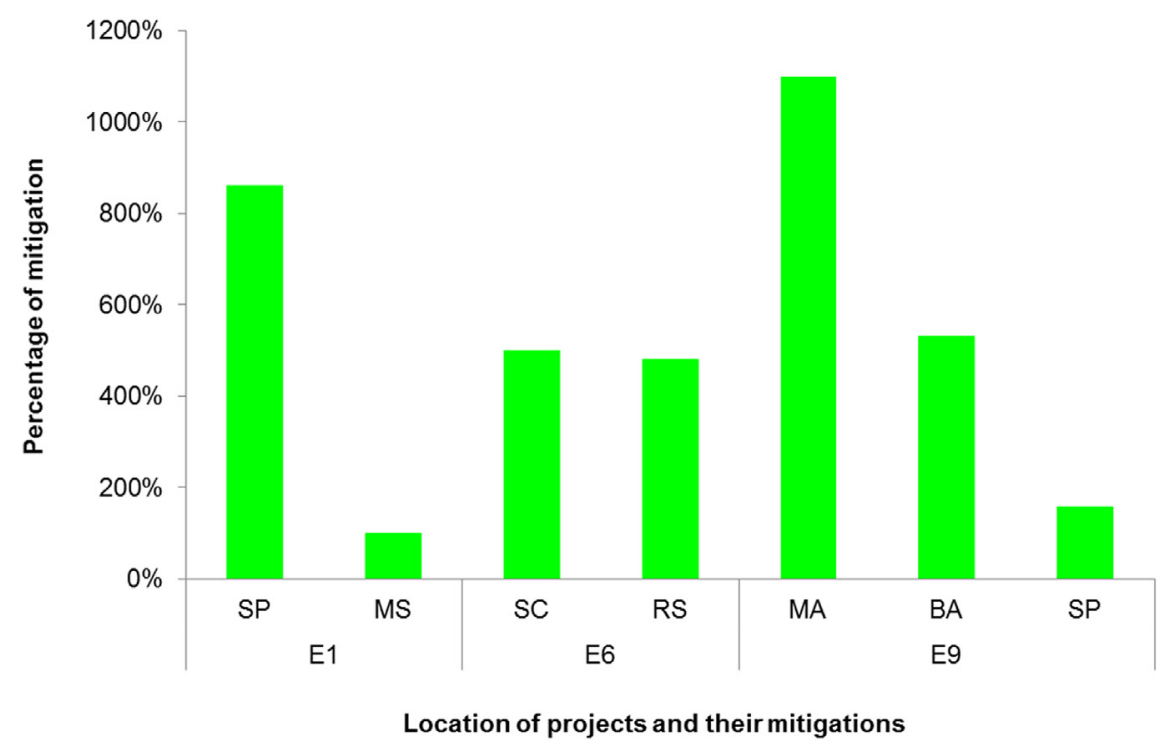

Fig. 7. Grouped subsidiaries of companies (except financial institutions) that mitigated $100 \%$ of the $B C A_{\text {min }}$ through $B C A_{\text {achieved }}$ development.

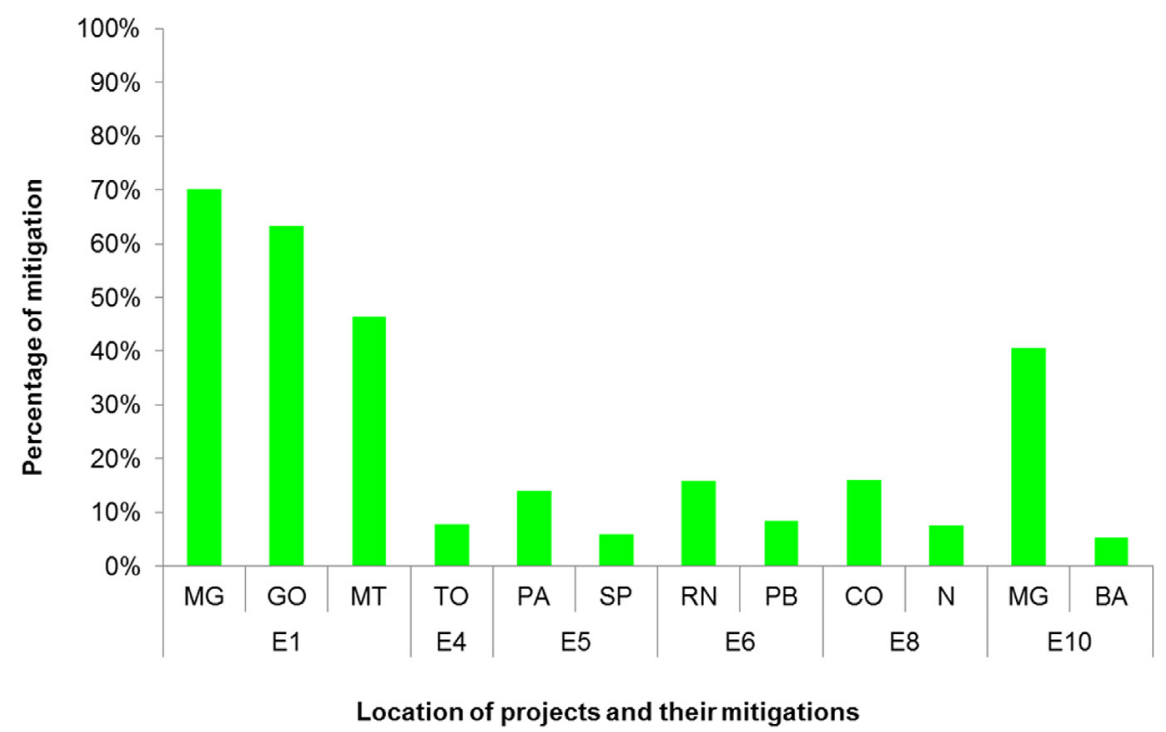

Fig. 8. Sample subsidiaries of companies (except financial institutions) that mitigate between $5 \%$ and $70 \%$ of the $B C A_{\text {min }}$ through $B C A_{\text {achieved }}$ development. 
GRI-4G, that is, only indicating whether biodiversity conservation activities were developed or were not developed. In this format of the report, more detailed information is not necessary, which might have committed the disclosure according to the criteria of the GRI. Nonetheless, this is prejudicial to investors who read the socioenvironmental reports to analyze where to invest their capital.

\section{Conclusions}

We demonstrated, quali-quantitatively, which of the 11 companies recognized as having the best sustainable practices of B3 generated environmental impacts on biodiversity, biomes, and ecosystem services, but only company E9 (paper/cellulose industry), effectively mitigated their minimum impacts through the development of biodiversity conservation actions. In addition, this is a unique company that shows, in fact, concern for conservation, restoration, and the maintenance of ecosystems and is therefore unique in their effective sustainable management of ecosystems.

To mitigate the impacts occasioned by production processes, it is necessary that a company develops direct actions in the affected biome, implanting or developing, preferably, conservation activities within protected areas, thus ensuring the continuity of ecosystem services according to the LIFE method.

Some subsidiaries of the analyzed companies have concerns with sustainability precepts once their externalities $\left(\mathrm{BCA}_{\min }\right)$ were mitigated by biodiversity conservation actions ( $\left.B C A_{\text {achieved}}\right)$, generating benefits to the environment, economy, and society. These subsidiaries can be considered as having included biodiversity transversally in their management because their externality scores are, at a minimum, equal to the mitigation actions achieved.

The socio-environmental report in 2014 of company E9 had only 64 pages and received $77 \%$ of the total points in $\mathrm{BCA}_{\text {achieved }}$ calculated in this study. On the other hand, company E2, which did not develop $\mathrm{BCA}_{\text {achieved}}$, divulged the largest report, with 310 pages. That may indicate that enterprises disclose reports without precision and details of the developed actions, compromising the reliability of the information presented, even though these companies were accredited by the GRI and in the 10th consecutive year in the ISE portfolio of the B3.

As the LIFE certification methodology shows, to create or to adopt natural protected areas (officially or not yet officially recognized) generates high scores of $\mathrm{BCA}_{\mathrm{achieved}}$, since protecting natural fauna and flora of the region allows ecosystems to continue to provide ecosystem services. Thus, biodiversity conservation actions can be used by companies as a way to pay to the ecosystem for natural resource exploration or use. That means that developing biodiversity conservation actions is one way to maintain ecosystem provisions and our life quality on the planet. However, these actions need be considered as an investment in our continuing existence in the world. Although the results have been weak, the fact that companies divulged sustainable reports indicate that they would like to improve their management to sustainable precepts, but possibly in a slow way because they do not understand the real environmental situation.

Finally, the LIFE methodology can be considered an additional tool for environmental management, indicating areas in which a company has the potential to improve management through the calculus of partial results of externalities. Also, the methodology allows for the strengthening of transparency of sustainability of companies on the B3 and society as a whole, once the mitigation of environmental impacts through biodiversity conservation actions contributes to promoting the resilience and resistance of ecosystems, allowing the maintenance of ecosystem services, generating social welfare, economic consciousness and environmental equilibrium.

\section{Acknowledgments}

We thank LIFE Institute for providing worksheets; Dr. Regiane Borsato and Professor Dr. João Gomes Martines Filho by the first review of this manuscript. This work was financial supported by the 'Coordenação de Aperfeiçoamento de Pessoal de Nível Superior' (CAPES).

\section{Appendix A. Supplementary data}

Supplementary data related to this article can be found at http:// dx.doi.org/10.1016/j.jclepro.2017.09.123.

\section{References}

Andam, K.S., Ferraro, P.J., Pfaff, A., Sanchez-Azofeifa, G.A., Robalino, J.A., 2008. Measuring the effectiveness of protected area networks in reducing deforestation. Proc. Natl. Acad. Sci. 105, 16089-16094. http://dx.doi.org/10.1073/ pnas.0800437105.

Auffret, A.G., Plue, J., Cousins, S.A.O., 2015. The spatial and temporal components of functional connectivity in fragmented landscapes. Ambio 44, 51-59. http:// dx.doi.org/10.1007/s13280-014-0588-6.

Beato, R.S., de Souza, M.T.S., Parisotto, I.R. dos S., 2009. Rentabilidade dos índices de sustentabilidade empresarial em bolsas de valores: UM estudo do ise/bovespa. Rev. Adm. Inovação 6, 108-127. http://dx.doi.org/10.5585/rai.v6i3.472.

Bello, C., Galetti, M., Pizo, M.A., Magnago, L.F.S., Rocha, M.F., Lima, R.A.F., Peres, C.A., Ovaskainen, O., Jordano, P., 2015. Defaunation affects carbon storage in tropical forests. Sci. Adv. 1, e1501105 http://dx.doi.org/10.1126/sciadv.1501105.

Cardinale, B.J., Duffy, J.E., Gonzalez, A., Hooper, D.U., Perrings, C., Venail, P., Narwani, A., Mace, G.M., Tilman, D., Wardle, D.A., Kinzig, A.P., Daily, G.C., Loreau, M., Grace, J.B., Larigauderie, A., Srivastava, D.S., Naeem, S., 2012. Biodiversity loss and its impact on humanity. Nature 486, 59-67. http:// dx.doi.org/10.1038/nature11148.

Chapin III, F.S., Zavaleta, E.S., Eviner, V.T., Naylor, R.L., Vitousek, P.M., Reynolds, H.L., Hooper, D.U., Lavorel, S., Sala, O.E., Hobbie, S.E., Mack, M.C., Díaz, S., 2000. Consequences of changing biodiversity. Nature 405, 234-242. http://dx.doi.org/ $10.1038 / 35012241$.

Dobrovolski, R., Rattis, L., 2015. Water collapse in Brazil: the danger of relying on what you neglect. Nat. Conserv. 13, 80-83. http://dx.doi.org/10.1016/ j.ncon.2015.03.006.

Instituto LIFE, 2014a. LIFE-BR-TG01-3.0-English (No. 3.0) (Curitiba).

Instituto LIFE, 2014b. LIFE-BR-TG02-3.0-English (No. 3.0) (Curitiba).

Instituto LIFE, 2012. HISTÓRICO DE DESENVOLVIMENTO DOS PADRÕES LIFE E DA METODOLOGIA DE. Certificação LIFE, Curitiba.

IPCC, 2014. Climate Change 2014: Mitigation of Climate Change. Contribution of Working Group III to the Fifth Assessment Report of the Intergovernmental Panel on Climate Change. Cambridge University Press, Cambridge, United Kingdom and New York. NY, USA, Cambridge, United Kingdom and New York, NY, USA).

Isbell, F., Craven, D., Connolly, J., Loreau, M., Schmid, B., Beierkuhnlein, C., Bezemer, T.M., Bonin, C., Bruelheide, H., de Luca, E., Ebeling, A., Griffin, J.N., Guo, Q., Hautier, Y., Hector, A., Jentsch, A., Kreyling, J., Lanta, V., Manning, P., Meyer, S.T., Mori, A.S., Naeem, S., Niklaus, P.A., Polley, H.W., Reich, P.B., Roscher, C., Seabloom, E.W., Smith, M.D., Thakur, M.P., Tilman, D., Tracy, B.F., van der Putten, W.H., van Ruijven, J., Weigelt, A., Weisser, W.W., Wilsey, B., Eisenhauer, N., 2015. Biodiversity increases the resistance of ecosystem productivity to climate extremes. Nature 526, 574-577. http://dx.doi.org/10.1038/ nature15374.

Marcondes, A.W., Bacarji, C.D., 2010. ISE: Sustentabilidade no mercado de capitais, first ed. Report Editora, São Paulo.

Rambaldi, D.M., de Oliveira, D.A.S., 2003. Fragmentação de Ecossistemas: Causas, efeitos sobre a biodiversidade e recomendações de políticas públicas. MMA/SBF, Brasília.

Reale, R., Ribas, L.C., Borsato, R., Magro, T.C., Voigtlaender, M., 2016. The LIFE certification methodology as a diagnostic tool of the environmental management system of the automotive industry. Environ. Sci. Policy 57, 101-111. http:// dx.doi.org/10.1016/j.envsci.2015.12.009.

Ribeiro, M.C., Metzger, J.P., Martensen, A.C., Ponzoni, F.J., Hirota, M.M., 2009. The Brazilian Atlantic Forest: how much is left, and how is the remaining forest distributed? Implications for conservation. Biol. Conserv. 142, 1141-1153. http:// dx.doi.org/10.1016/j.biocon.2009.02.021.

Rossi, J.L., 2009. What is the value of corporate social Responsibility? An answer from the Brazilian sustainability index. SSRN Electron. J. 1-18. http://dx.doi.org/ 10.2139/ssrn.1338114.

Scarano, F.R., Ceotto, P., 2015. Brazilian Atlantic forest: impact, vulnerability, and adaptation to climate change. Biodivers. Conserv. 24, 2319-2331. http:// dx.doi.org/10.1007/s10531-015-0972-y.

Sheil, D., Murdiyarso, D., 2009. How forests attract rain: an examination of a new hypothesis. Bioscience 59, 341-347. http://dx.doi.org/10.1525/bio.2009.59.4.12. Sícoli, C.E., Alexandre, S., Sebbenn, M., Kageyama, P.Y., 2005. Sistema de reprodução 
em duas populações naturais de Euterpe edulis M. sob diferentes condições de fragmentação florestal. Sci. For. IPEF 69, 13-24.

Sukhdev, P., Wittmer, H., Schöter-Schlaack, C., Nesshöver, C., Bishop, J., ten Brink, P., Gundimeda, H., Kumar, P., Simmons, B., Neuville, A., 2010. A Economia dos Ecossistemas e da Biodiversidade: Integrando a Economia da Natureza. Uma síntese da abordagem, conclusões e recomendações do TEEB. PNUMA e Confederação Nacional da Indústria, Genebra.

UNFCCC. Conference of the parties (COP), 2015. adoption of the Paris agreement. proposal by the President., in: Paris Climate Change Conference - November 2015, COP 21. Paris, p. 32.

Vincent, J.R., Carson, R.T., DeShazo, J.R., Schwabe, K.A., Ahmad, I., Chong, S.K.,
Chang, Y.T., Potts, M.D., 2014. Tropical countries may be willing to pay more to protect their forests. Proc. Natl. Acad. Sci. 111, 10113-10118. http://dx.doi.org/ 10.1073/pnas.1312246111.

Williams, N.M., Crone, E.E., Roulston, T.H., Minckley, R.L., Packer, L., Potts, S.G., 2010 Ecological and life-history traits predict bee species responses to environmenta disturbances. Biol. Conserv. 143, 2280-2291. http://dx.doi.org/10.1016 j.biocon.2010.03.024.

Zolin, C.A., Folegatti, M.V., Mingoti, R., Paulino, J., Sánchez-Román, R.M., González, A.M.O., 2014. The first Brazilian municipal initiative of payments for environmental services and its potential for soil conservation. Agric. Water Manag. 137, 75-83. http://dx.doi.org/10.1016/j.agwat.2014.02.006. 